\title{
Inflammatory myofibroblastic tumour of the mandible - A case report
}

\author{
*Dr.Mohammad Asifur Rahman ${ }^{1}$
}

\section{AFFILIATION:}

1. Dr.Mohammad Asifur Rahman, BDS, MS(OMS)

Assistant Professor,

Department of Oral \& Maxillofacial Surgery,

Dhaka Dental College Hospital, Dhaka, Bangladesh

\section{Article info.}

Received: 02 December 2019

Accepted: 15 January 2020

Volume: 10, Issue-1 April, 2020

DOI: https://doi.org/10.3329/updcj.v10i1.46688

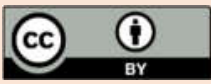

(C) Authors retain copyright and grant the journal right of first publication with the work simultaneously licensed under Creative Commons Attribution License CC - BY 4.0 that allows others to share the work with an acknowledgment of the work's authorship and initial publication in this journal.

https://creativecommons.org/licenses/by/4.0/

Publisher: Update Dental College, Dhaka, Bangladesh

Web: www.updatedentalcollege.edu.bd

E-mail: updci@hotmail.com

* Corresponding Author

Dr. Mohammad Asifur Rahman BDS, MS(OMS), Assistant Professor, Department of Oral \& Maxillofacial Surgery, Dhaka Dental College \& Hospital, Dhaka, Bangladesh E-mail: asiff.omfs@gmail.com

\begin{abstract}
Inflammatory myofibroblastic tumour (IMT) is an extremely rare, benign softtissue lesion of unknown aetiology and pathogenesis that mimics malignant lesions clinically and radiologically found in the maxillofacial region. It occurs primarily in the lungs but occurred in other extra-pulmonary sites. Histologically these lesions appear as an inflammatory infiltrate within a variable of myofibrotic background. The current mode of treatment for inflammatory myofibroblastic tumour (IMT) is surgical excision with regular follow up.

In this case report a 40 years old female presented with an intraosseous inflammatory myofibroblastic tumour (IMT) in the left side of mandible which was treated by surgical excision of the lesion. This article also describes the clinicopathological features and treatment of a case of inflammatory myofibroblastic tumour (IMT) of the mandible.
\end{abstract}

\section{KEYWORDS: Inflammatory myofibroblastic tumour, Jaw tumor,}

\section{INTRODUCTION}

Inflammatory myofibroblastic tumour (IMT) is a rare, benign soft-tissue lesion characterized by aggressive proliferation of myofibroblastic spindle cells along with infiltrating inflammatory cells include plasma cells, histiocytes, fibroblasts, eosinophils and lymphocytes. ${ }^{1,2}$

Inflammatory myofibroblastic tumour (IMT) is a very rare lesion and more rare in the maxillofacial region. ${ }^{3}$ It was first observed in the lung and described by Brunn in 1939 and named by Umiker et al. in 1954 because of its clinical and radiological behaviour that mimics a malignant process. ${ }^{4}$ In 1984 it was first described and underwent changes in its name for the next 10 years until the World Health Organization (WHO) settled on the current terminology in $1994 .^{3}$

The etiology and pathogenesis of inflammatory myofibroblastic tumours (IMT) have not been explicated clearly and remains unclear because clinically and radiologically it mimic a malignant process. ${ }^{5}$

Inflammatory myofibroblastic tumours (IMT) are most commonly observed in the lungs followed by the abdomen, retroperitoneum and extremities. In the head and neck region inflammatory myofibroblastic tumours (IMT) are rare and represent $14-18 \%$ of all extra-pulmonary inflammatory myofibroblastic tumours (IMT). In the oral cavity it is exceedingly rare but cases of inflammatory myofibroblastic tumours (IMT) in the retromolar and pterygopalatine area, tongue, maxilla, hard palate, mandible, floor of the mouth, buccal cheek, major salivary glands and the soft tissues of the neck have been reported. ${ }^{6}$

The lesion has a nonspecific clinical and radiographic presentation and exhibits aggressive growth which giving rise to clinical suspicions of malignancy. ${ }^{6}$ Histopathology and immunohistochemistry are critical in the diagnosis of inflammatory myofibroblastic tumours (IMT). ${ }^{7}$ So Appropriate 
management of inflammatory myofibroblastic tumours (IMT) can be delayed due to a challenging differential diagnoses. ${ }^{6}$ In this case report, I present a rare case of an intraosseous inflammatory myofibroblastic tumour (IMT) in the left side of mandible which was treated by surgical excision of the lesion.

\section{CASE REPORT}

A 40 years old female patient reported to the Department of Oral and Maxillofacial Surgery, Dhaka Dental College \& Hospital, Dhaka, Bangladesh, presented with a history of slow growing, painless enlarging growth in the left posterior mandible for several months. The lesion was a well circumscribed, raised sessile mass and the same colour as the surrounding mucosa in the area between teeth numbers of lower left 6 and 7. There was no bleeding or exudates in the area.

Physical examination revealed extra-oral swelling in the left lower third of the face extending from the angle of the mouth to the mandibular angle. In palpation, the mandibular swelling was firm in consistency and mandibular posterior teeth were mobile with loss of sensation in the left side of her lower lip

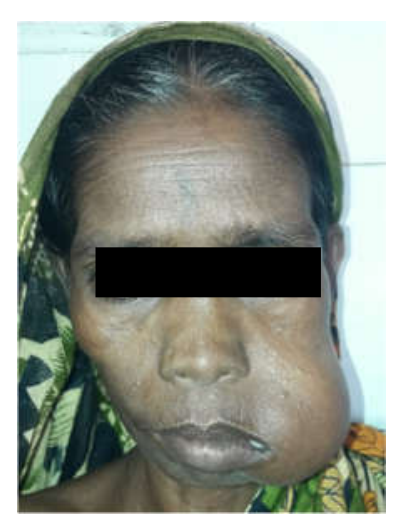
and chin area.

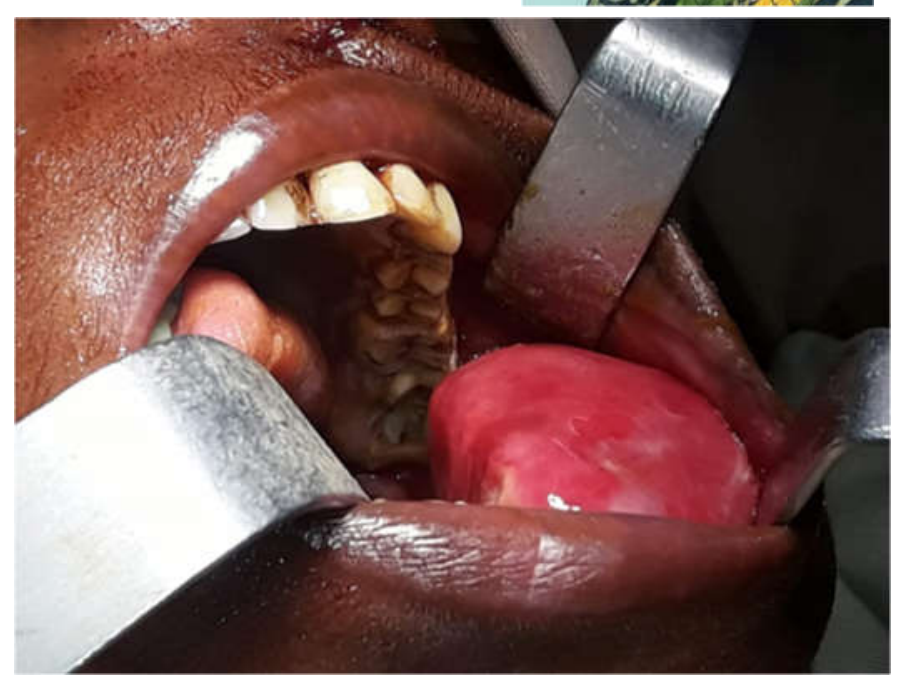

Fig 1, 2. Extaoral view - swelling of the face extending from the angle of the mouth to the mandibular angle. (From Uper left to right)

Fig 3. Intraoral view well circumscribed, raised sessile mass and the same colour as the surrounding mucosa in the left mandible (Below)
Clinical examination revealed a $7 \times 9 \mathrm{~cm}$ well circumscribed, raised sessile mass and the same colour as the surrounding mucosa in the left mandible. The mass extended from the lower first molar to the central incisor and involved both buccal and lingual surfaces almost covering the occlusal aspects of the teeth. The swelling was firm in consistency and there was no tender on palpation. (Fig. 3)

Her oral hygine was below average. Systemic examination was unremarkable. There was no evidence of cervical lymphadenopathy. The patient's medical and social history was non-contributory and she did not receive any medications. The lesion presented as an asymptomatic, intraosseous lesion in the left mandibular molar region as demonstrated by orthopantomographs (OPG). Radiographic evaluation revealed a well-circumscribed radiolucent circular lesion in the area between teeth numbers of lower left 5 and 6. (Fig.4)

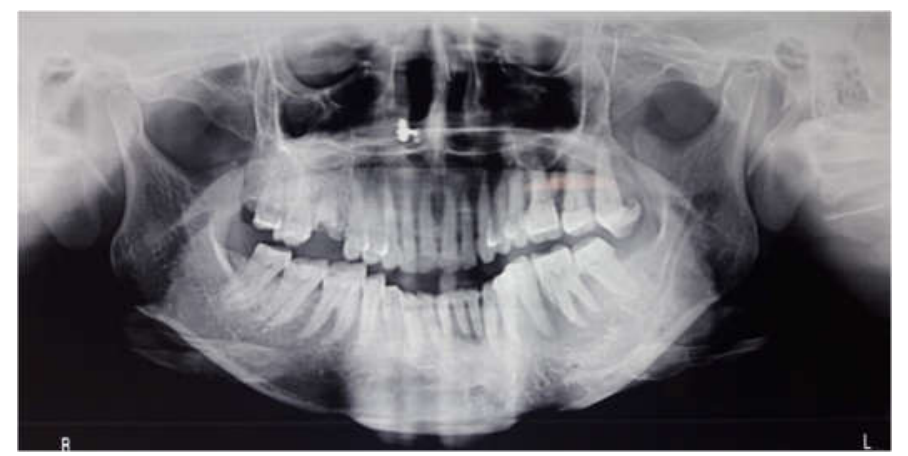

Fig 4. Well-circumscribed radiolucent circular lesion in the area between lower left 5 and 6 number teeth

Computed tomography of the mandible in the transverse plane revealed a hypodense area involving the molar region. Three dimensional CT scan reconstruction confirmed this to be an osteolytic lesion which necessitated the incisional biopsy at representative area.

The initial clinical differential diagnosis was pyogenic granuloma, fibroma, peripheral giant cell lesion, myxoma, Langerhans cell histiocytosis or lymphoma.

Histopathological examination revealed a highly cellular connective tissue stroma with the overlying epithelium. The cellular proliferation comprised of spindle shaped cells arranged in a fascicular growth pattern mixed with a dense inflammatory cell infiltrate consist of plasma cells, eosinophils, neutrophils and lymphocytes. The vascular component present as slit like spaces which was obscured by background cellularity.

A final diagnosis of inflammatory myofibroblastic tumour (IMT) was made on the base of radiological \& histopathological examination and treatment plan was made for surgical excision under general anaesthesia.

A surgical procedure was performed under general anaesthesia after taking informed written consent from the patient. A mucosal incision was given below the mucogingival junction adjacent to the left first mandibular pre molars. A fullthickness mucoperiosteal flap was then reflected. The lesion was then visually located and appeared solid and red in colour. The lesion was removed and easily separated from the 
surrounding bone. A bur was then used to remove a portion of the buccal and lingual cortical bone in the area of the molar region. The cavity was irrigated with normal saline and was closed primarily. (Fig.5, 6, 7)
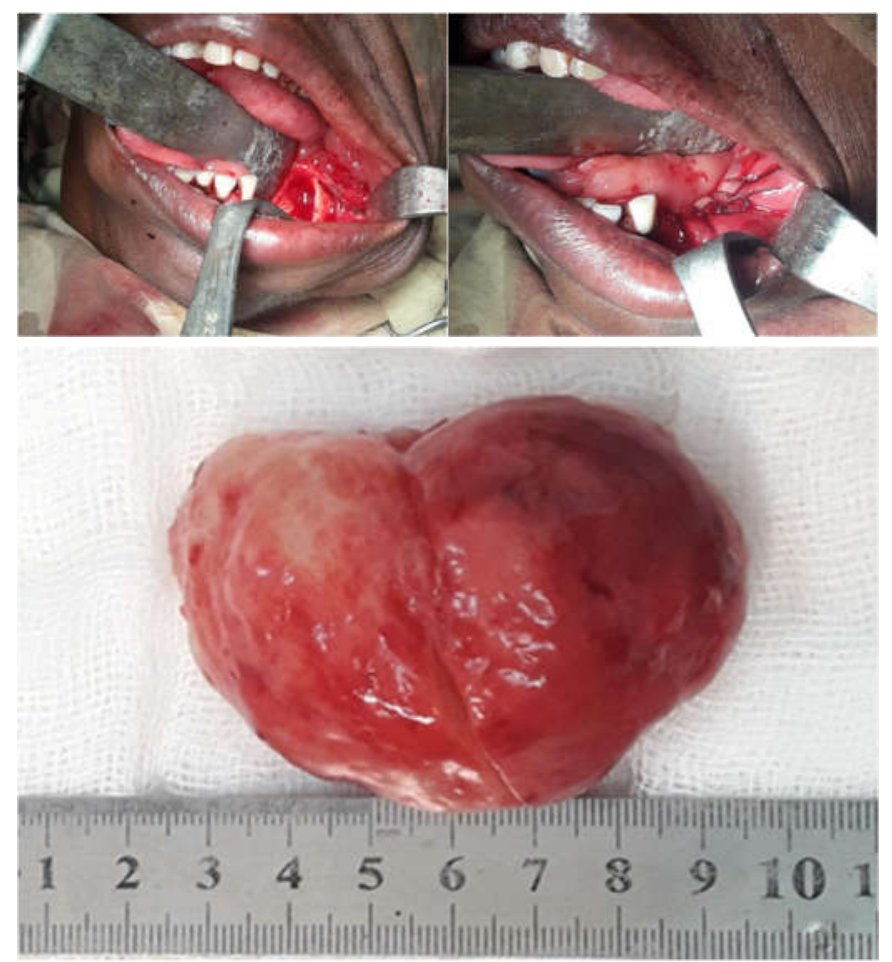

Fig 5, 6. Surgical excision of lesion and closure after surgical excision of lesion Fig 7. Specimen after surgical excision (From upper left to right and below)

Post operatively the patient was put on nasogastric feeding tube for 5 days. Antibiotics and analgesics were prescribed 3 times daily for 7 days. The patient was assessed postoperatively every day until discharged from the hospital.

The postoperative histopathological examination of the specimen revealed same reports when incisional biopsy was done and final diagnosed was inflammatory myofibroblastic tumour (IMT).

The patient was regular followed up and demonstrated no clinical or radiologic evidence of recurrence. Postoperative OPG demonstrates improved healing of the surgical site with evidence of new bone formation. The patient does not report any clinical symptoms or any signs of recurrence of the lesion.

\section{DISCUSSION}

Inflammatory myofibroblastic tumours (IMT) is predominantly a tumour of the viscera. ${ }^{8}$ It is an extremely rare tumour in the head and neck region with only few cases that have been reported in different oral cavity sites including intra and extraosseous sites..$^{5}$

Demographically the lesion exhibits a wide ranges - a mixture of males and females with an age range between 19 and 77 years. ${ }^{9}$ But inflammatory myofibroblastic tumours (IMT) shows a distinct predilection for children and young adults. Oral lesions develop over a short duration of time and often exhibit a disturbingly rapid growth rate. ${ }^{10}$ In this case report, the patient was middle aged women and her oral lesion 23 | P a g e developed over a short duration of time and exhibit a rapid growth rate.

The etiopathogenesis of inflammatory myofibroblastic tumours (IMT) remains unresolved. These lesions were traditionally considered a benign reactive process, possibly as an exaggerated immune response to trauma, Epstein-Barr virus, human herpes virus- 8 , surgery or a foreign body. ${ }^{10}$ The etiopathogenesis of inflammatory myofibroblastic tumour (IMT) was not investigated in the present case.

Inflammatory myofibroblastic tumours (IMT) are tumours with unpredictable clinical behaviour, requiring complete surgical excision and continuous monitoring of clinical consequences. ${ }^{4}$ Medical management including corticosteroids are not effective in head and neck lesions while considered in the management of orbital inflammatory myofibroblastic tumours (IMT). ${ }^{4}, 11$ There is no evidence of recurrence, malignant transformation, metastasis or death reported with oral inflammatory myofibroblastic tumours (IMT). ${ }^{12}$

The controversial treatment options of the neoplastic nature of inflammatory myofibroblastic tumours (IMT) is surgical excision, curettage, corticosteroid therapy, radical surgery and radiotherapy. ${ }^{10}$ Although there are no prospective studies reported in the literature specify the treatment protocols for inflammatory myofibroblastic tumours (IMT) - the best prognosis have been documented following radical surgical resection with negative margins were associated with $87 \%$ reduction in mortality and considered it as the most important prognostic indicator for local recurrence. ${ }^{2}$

Complete surgical excision was the only treatment modality employed in this case. During 24 months of post-operative follow up period the patient developed no clinical or radiographic signs of recurrence.

\section{CONCLUSION}

In the present case the lesion was affecting the left mandible, complete surgical excision of the lesion appears to have been curative with no signs of recurrence over 24 months of postoperative follow up period.

Inflammatory myofibroblastic tumours in the oral cavity may be confused with other malignant tumours on clinical, radiographic, and histologic appearance. So Oral \& Maxillofacial surgeons should be aware that inflammatory aggressive tumours of the head and neck including the oral cavity. In clinical practice, the surgeons may require special attention for prompt diagnosis, management and regular follow up of such a rare tumours with unusual presentation.

\section{REFERENCES:}

1. Cho SI, Choi JY, Do NY, Kang CY, 2008. An inflammatory myofibroblastic tumor of the nasal dorsum. J. Pediatr. Surg. 43. https://doi.org/10.1016/i.jpedsurg.2008.09.015

PMid:19040918

2. Ong HS, Ji T, Zhang CP, Li J, Wang LZ, Li RR et al. Head and neck inflammatory myofibroblastic tumor (IMT): evaluation of clinicopathologic and prognostic features. Oral Oncol. 2012; 48, 141 . 148. https://doi.org/10.1016/j.oraloncology.2011.09.004 PMid:22014665

Website: https://www.banglajol.info/index.php/UpDCJ 
3. Dale E. Stringer, Chad N. Allen, Katina Nguyen, and Rahul Tandon. Intraosseous Inflammatory Myofibroblastic Tumor in the Mandible: A Rare Pathologic Case Report Hindawi Publishing Corporation Case Reports in Surgery. Volume 2014.

https://doi.org/10.1155/2014/565478

PMid:25254136 PMCid:PMC4165562

4. Narla LD, Newman B, Spottswood SS, Narla S, Koll IR. Inflammatory pseudotumor. Radiographics. 2003; 23: 719 - 29.

https://doi.org/10.1148/rg.233025073

PMid:12740472

5. Binmadi Nada O, Packman, Harold, Papadimitriou, John C, Scheper, Mark. Oral inflammatory myofibroblastic tumor: case report and review of literature. Open Dent. J. 2011; 5, 66 - 70. https://doi.org/10.2174/1874210601105010066

PMid:21566695 PMCid:PMC3091292

6. AlKindi GM. A rare case of inflammatory myofibroblastic tumor of the mandible mimicking a malignant tumor The Saudi Dental Journal. 2017; 29, $36 \quad-40 \quad$ https://doi.org/10.1016/i.sdentj.2016.10.001 PMid:28270708 PMCid:PMC5324014

7. Ma L, Wang K, Liu WK, Zhang YK. Is radical surgery necessary to head and neck inflammatory myofibroblastic tumor (IMT) in children? Child's Nerv. Syst. 2009; 25, 285 - 291 https://doi.org/10.1007/s00381-008-0718-1 PMid:18830608

8. Gleason BC, Hornick JL. Inflammatory myofibroblastic tumours: where are we now? J Clin Pathol. 2008; 61: 428 - 37.

https://doi.org/10.1136/jcp.2007.049387 PMid:17938159

9. A.Date, K. Yamagata, K. Onizawa et al. Inflammatory pseudotumor: report of a case in the mandible, Oral andMaxillofacial Surgery. 2012; vol. 16, no. 1, pp. 65-68. https://doi.org/10.1007/s10006-010-0250-9 PMid:20978812

10. Sah P, Byatnal AA, Rao L, Narayanaswamy V, Radhakrishnan R. Inflammatory Myofibroblastic Tumor : A Rapidly Growing Soft Tissue Mass in the Posterior Mandible Head and Neck Pathol. 2013; 7:393 - 397 https://doi.org/10.1007/s12105-013-0474-8

PMid:23843049 PMCid:PMC3824806

11. Van Weert S, Manni JJ, Driessen A. Inflammatory myofibroblastic tumor of the parotid gland: case report and review of the literature. Acta Otolaryngol. 2005; 125: 433 - 7.

https://doi.org/10.1080/00016480410025225

PMid:15823818

12. Shek AW, Wu PC, Samman N. Inflammatory pseudotumour of the mouth and maxilla. J Clin Pathol. 1996; 49: 164 - 7. https://doi.org/10.1136/icp.49.2.164 PMid:8655685 PMCid:PMC500352 